Postprint of: RAND Journal of Economics, 49(1), 2018, 206-223.

\title{
Consumer Obfuscation by a Multiproduct Firm*
}

\author{
Vaiva Petrikaitè $\dot{\mathrm{C}}^{\dagger}$
}

2017 September

\begin{abstract}
This paper shows that a multiproduct firm has incentives to obfuscate its products by using search costs to induce consumers to search through its products in a particular order. The consumers who draw high valuations of the first product terminate their search earlier than the consumers who draw low valuations. Thus, the firm has incentives to raise the price of the earlier-searched product. The optimal search cost for an obfuscated product is such that consumers inspect the product only if the match values of the previously-searched goods have been very poor.
\end{abstract}

Keywords: Sequential search, obfuscation, horizontal differentiation, search costs, multiproduct firm

JEL classification: D21, D42, D83

${ }^{*}$ I want to express my enormous gratitude to two anonymous referees and the editor for their patience, comments, additional questions and suggested examples. I am also extremely grateful to José Luis Moraga-González for his advice while writing this paper. Additionally, I thank Marco Haan, Shu Yu, Wim Siekman, Dominic Hauck, Christopher Wilson, Irina Stanga, Saara Hämäläinen, Andrew Rhodes, Michalis Zaouras, Gianni de Fraja, Francesc Dilme, Vincente Cuñat, Michael Waterson, Sandro Shelegia, Aidas Masiliūnas, Sjaak Hurkens, Roberto Burguet, the participants of the seminars at Universität Düsseldorf (DICE), Pompeu Fabra University, the Insitute of Economic Analysis (CSIC), the University of Lancaster, the University of Cardiff, the University of Durham, the $V^{\text {th }}$ Consumer Search and Switching Workshop and EARIE-2013 for their helpful comments and suggestions. The author acknowledges the financial support of the Spanish Ministry of Economics, Grants No. ECO2014-59959-P and ECO2015-74328-JIN (AEI/FEDER/UE).

${ }^{\dagger}$ Instituto de Análisis Económico (CSIC) and Barcelona GSE, Campus UAB, 08193 Bellaterra, Barcelona, Spain. E-mail: asvaiva@gmail.com 


\section{Introduction}

Knowledge of individual customer preferences and the ability to set personal prices allow firms to collect higher sales revenues. However, such marketing approaches may not be feasible in some markets due to the cost of data gathering and consumer privacy concerns. In these cases, firms need to apply other customer screening techniques.

This paper provides a formal analysis of one such technique, whereby a multiproduct firm can imperfectly screen its customers' preferences by obfuscating its products. In particular, the paper considers a model where consumers have unit demand and differ in their random valuations of products, as in Perloff and Salop (1985). The firm chooses a set of prices and may obfuscate its products by setting product-specific search costs. To learn the prices and match values of the products, consumers must then engage in a costly sequential search process, as in Wolinsky (1986) and Anderson and Renault (1999). This paper shows that, in equilibrium, a multiproduct monopolist sets positive search costs for some products and thereby makes a consumer sample the products in a particular order by starting with the less obfuscated goods. This ordered search encourages consumers to self-sort according to their valuations. The average valuation of a product by consumers who buy the good decreases in the search order. Thus, the monopolist sets higher prices for products searched for earlier and lowers the prices for those searched for later.

In reality, firms are obliged to inform consumers about their products before purchasing. However, they are relatively free in choosing the way in which they provide this information. As a result, obfuscation often appears in practice. For instance, supermarkets do not create artificial search frictions but exploit limited shelf space in placing products with different profit margins. According to Derbyshire (2004), products that are placed at eye level are more expensive than those that are at the bottom or at the top of a shelf. Similarly, Mannino (2012) observes that "[retailers] know shoppers want to easily find the size, price and item neatly displayed. So they purposely create the frustration of the poorly marked and poorly organized clearance area to tempt you toward the beautifully displayed and perfectly organized full-price merchandise." ${ }^{1}$ In her book, Mitford (1963) describes how coffin sellers lead their customers to more expensive items first, and later they introduce the consumers to cheaper options. Additionally, online retailers often put special links to their new arrivals on the first pages of their online shops during regular seasons, as these new arrivals provide higher profit margins, and consumers observe them sooner and more easily than other products. Further, Anagol et al. (2013) and Bergstresser et al. (2009) show that insurance agents and financial advisors often offer their customers products that have higher commission fees and do not necessarily satisfy best the needs of a customer, in which case the customer has to put additional

\footnotetext{
${ }^{1}$ The same was found in the experimental study of Dréze et al. (1994) and by BBC Watchdog who drew consumers' attention to the fact that supermarkets placed cheaper options in less prominent positions that required additional effort to find them (source: http://www.bbc.co.uk/watchdog/consumer_advice/supermarket_psychology.shtml; accessed 2013 Jul.).
} 
effort into learning more about the alternatives.

Besides the main analysis with symmetric products, this paper also studies how a multiproduct firm obfuscates goods that differ in quality or design. To model quality and design differences, I adopt the method of Johnson and Myatt (2006) and Bar-Isaac et al. (2012) based on the rotation of distribution functions. The analysis shows that the monopolist obfuscates the product more that attracts fewer consumers absent obfuscation. Thus if two products are differentiated vertically, the monopolist obfuscates the good of lower quality. Meanwhile, whether a mass or a niche market product is obfuscated depends on the distribution of the products' valuations.

Additionally, the paper covers a couple of extensions of the basic model, which consider observable prices and differences in production costs. It is shown that price observability does not eliminate the incentives to obfuscate. In the case of different production costs, the seller sets a higher search cost for the product that is chosen by fewer consumers absent obfuscation, which, given identical distributions of the valuations, is a product with higher marginal production costs.

This paper contributes to the recent economics literature on obfuscation by studying the subject within a multiproduct firm as a mechanism for screening consumer preferences. So far, existing studies have focused on obfuscation as an instrument employed to decrease competitive pressure among firms (Wilson (2010) and Ellison and Wolitzky (2012)). In those models, firms sell homogeneous products. Consumers incur search costs when learning about prices, and the degree of obfuscation is either unobservable (Ellison and Wolitzky, 2012) or known (Wilson, 2010) to consumers a priori. Both Wilson (2010) and Ellison and Wolitzky (2012) find that obfuscation decreases competitive pressure and therefore firms earn more profits if they follow this strategy.

Other papers consider intra-firm obfuscation by a multiproduct firm. Closest to that of the present paper are Gu and Liu (2013), Gamp (2016) and Salop (1977). Gu and Liu (2013) show that a monopolist retailer may use obfuscation in the retail market to make the manufacturers pay for prominent positions. In that study, the retailer charges the same price for all the products and focuses on the upstream market. ${ }^{2}$ In the model of Salop (1977), a multiproduct monopolist screens consumers according to their valuations by using their differences in search costs. Gamp (2016) also analyses obfuscation and the price choices of a multiproduct monopolist with horizontally differentiated products. Unlike the present paper, he places fewer restrictions on the distributions of match values and focuses on markets with more than two products and observable prices. For these reasons, some of his results and welfare findings differ from the present paper, including showing that obfuscation might improve welfare.

By obfuscating some of its products, the monopolist controls the order in which its goods are sampled. In this sense, the present paper is related to the literature on ordered searching. Arbatskaya (2007) shows that when consumers shop for homogeneous products, equilibrium prices must fall as a consumer proceeds to search for lower prices. Zhou (2011) demonstrates that when consumers

\footnotetext{
${ }^{2}$ Iyer and Kuksov (2012) observe that firms never over-invest in shopping experiences that decrease the search costs of consumers compared to the social optimum, when the shopping experience is a substitute for price advertising.
} 
shop for differentiated products, equilibrium prices increase instead. Armstrong, Vickers, and Zhou (2009) explore the role of prominence in search markets and show that a prominent product is sold at a lower price relative to non-prominent products. The main difference between those papers and the present one is that this study focuses on the role of search frictions among the products provided by a single firm. Zhou (2009) also observes that a multiproduct monopolist earns higher profits if one of its products is prominent. My monopoly analysis extends his result by allowing the monopolist to choose the degree of obfuscation, and by treating differences in product quality and design. ${ }^{3}$

The decision of a firm to obfuscate its products is somewhat related to its decision to advertise its products. Therefore, in this sense the present paper is related to the work of Caminal (1996), Anderson and Renault (2006) and Wang (2017). In all three models, the decision to advertise affects consumers' decisions on whether to pay a costly visit to a firm, and the firm chooses the advertising option that leads to the highest possible consumer traffic. The major difference between those papers and the present one is that in those papers, a single product-advertising monopolist often earns less if fewer consumers search, whereas in the present paper, the multiproduct monopolist gains from consumers who decide not to search much, in that they buy products that are more expensive though less obfuscated. Janssen and Non (2009) show that there may be an equilibrium in a duopoly model with homogeneous products, in which advertising firms charge higher prices. Their result stems from the fact that consumers differ in their willingness to pay that is positively correlated with their search costs. In contrast in the present paper, there is no search cost differentiation across consumers.

By the fact that the mean valuation of a product by consumers who acquire the good decreases in the search order, my results resemble the findings of models with an inter-temporal price-discriminating monopolist (see e.g. Stokey, 1979, 1981; Bulow, 1982; Coase, 1972). However, unlike with that monopolist, its multiproduct obfuscating counterpart escapes competition with itself by using search costs. In particular, the inter-temporal price-discriminating monopolist must commit to a specific price schedule to discourage some high-valuation consumers from waiting for lower prices; otherwise the sales at high prices are too low, which makes such inter-temporal price discrimination unprofitable. In the model with obfuscating monopolist, optimal obfuscation makes consumers consider products myopically. Therefore, the monopolist may set a lower price for the more obfuscated product without loosing much revenue from the less obfuscated good.

Because the multiproduct seller introduces frictions to consumers when comparing products, the present paper relates to the literature on trade intermediaries (see, e.g. Hagiu and Jullien, 2011; Burguet et al., 2015; White, 2013). In that branch of the literature, an intermediary controls only the degree of obfuscation, and prices are under the control of other firms, whereas in the present paper the multiproduct monopolist sets both the profit-maximizing prices and the search costs.

The rest of this paper is organised as follows. The basic assumptions are listed in Section 2. In

\footnotetext{
${ }^{3}$ The role of search costs in multiproduct settings was also studied by Rhodes (2015), Shelegia (2011) and Zhou (2014). In those papers, too, the search costs are not under the control of the firms in question.
} 
Section 3, I analyse an obfuscating monopolist who sells two horizontally differentiated products. The incentives to obfuscate, when there are differences in product quality and design, are explored in Section 4. The robustness of the main result is checked in Section 5. Some concluding remarks and a discussion of interesting research prospects on the subject are in Section 6. The proofs of propositions and other derivations can be found in Appendix.

\section{The description of the market}

There is a unit mass of consumers on the demand side. A typical consumer has unit demand, and wants to buy one of two horizontally differentiated products. ${ }^{4}$ The utility of consumer $l$ who buys product $i$ is denoted by $u_{i l}$, and is the difference between a valuation (match value), $\varepsilon_{i l}$, and a price $p_{i}$ :

$$
u_{i l}=\varepsilon_{i l}-p_{i} .
$$

The match is consumer- and product-specific and cannot be observed by a seller. ${ }^{5}$ However, it is common knowledge that match values are distributed independently and identically among consumers and products in the interval $[0, \bar{\varepsilon}]$ according to a continuous and everywhere at least twice differentiable distribution function $F(\varepsilon)$ with a log-concave and everywhere positive density $f(\varepsilon)$. The outside option provides a consumer with zero utility.

A consumer wants to buy a product providing the highest non-negative utility. However, the customer cannot easily pick the product because of obfuscation: to observe the individual match value and the price of product $i$, the consumer must incur a search cost $s_{i}$. If a firm did not obfuscate, the consumer could see both match values and prices without any search frictions. The consumer searches the products sequentially with free recall. Thus, the customer applies the sequential search and stopping rules derived by Weitzman (1979), which I briefly summarize here.

Suppose that a consumer has observed net utility $u \geq 0$ and considers searching for the utility of product $i$. The customer expects that the product is priced at $p_{i}^{*}$ and the expected gain from searching for $\varepsilon_{i}-p_{i}$ equals $\int_{u+p_{i}^{*}}^{\bar{\varepsilon}}\left(\varepsilon_{i}-p_{i}^{*}-u\right) d F\left(\varepsilon_{i}\right)$. I denote the value of $u$ that equates this gain with $s_{i}$ by $x_{i}-p_{i}^{*}$. This value is called the reservation utility of product $i$. If $u \geq x_{i}-p_{i}^{*}$, the expected gain from the search is lower than the search cost, and the consumer should stop searching. However, if $u<x_{i}-p_{i}^{*}$, it is worthwhile for the customer to search for $\varepsilon_{i}-p_{i}$. Because of the outside option, the reservation utility $x_{i}-p_{i}^{*}$ cannot be negative. ${ }^{6}$ Otherwise the consumer would never

\footnotetext{
${ }^{4}$ I discuss consumer obfuscation when there are more than two products in the online appendix.

${ }^{5}$ To simplify the mathematical expressions, the consumer-specific index is not used in further derivations except where necessary.

${ }^{6}$ If the consumer is indifferent about searching for the utility of the product whose reservation utility equals zero and taking an observed alternative that provides zero utility, I assume that the consumer searches.
} 
search for $\varepsilon_{i}-p_{i}$. Therefore, it must be that $x_{i} \geq p_{i}^{*}$ or

$$
s_{i} \leq \int_{p_{i}^{*}}^{\bar{\varepsilon}}\left(\varepsilon-p_{i}^{*}\right) d F(\varepsilon) .
$$

I assume that the search cost includes any obstacles that a consumer encounters in learning how much she likes a product: travelling costs, waiting time to be served, navigating between shelves, conversations with sales assistants to obtain the necessary information, and so on.

Both products are sold by a monopolist. The firm employs constant returns to scale technology for the two products, and their identical marginal costs are normalized to zero. The game consist of two stages. In the first stage, the seller simultaneously sets the pairs of prices and search costs. In the second stage, consumers search for the utilities of the products and buy one of them if any. A consumer observes the search costs of both products just after entering the shop and expects that the price of a product not yet searched for equals its equilibrium price, i.e. the consumer holds passive beliefs about prices. ${ }^{7}$ The equilibrium values of prices and search costs are denoted by the superscript *.

As a result of the differences in expected prices and search costs, consumers follow a search order by sampling one product first, which I refer to as product 1 . The other product is referred to as product 2 . The monopolist cannot benefit by obfuscating both products, and so I set $s_{1}^{*}=0$ in the following. ${ }^{8}$

\section{Market equilibrium}

In this section, I derive the set of profit-maximizing prices $\left\{p_{1}^{*}, p_{2}^{*}\right\}$ and the search cost $s_{2}^{*}$ (or equivalently $x_{2}^{*}$ ) that the monopolist sets in equilibrium. I begin with a setting in which the firm does not obfuscate at all and charges the same price $p^{*}$ for both its products. ${ }^{9}$ In this instance, a consumer buys one of the two products if the highest $\varepsilon$ is not less than $p^{*}$, which happens with probability $1-F\left(p^{*}\right)^{2}$. Thus, $p^{*}$ solves $\max _{p} p\left(1-F(p)^{2}\right)$. The distribution of buyers between the two goods is illustrated by Figure 1a. In the vertically striped area, $\varepsilon_{1}$ exceeds $\varepsilon_{2}$, and consumers whose valuations of both goods are in this area buy product 1. Similarly, the consumers whose valuations of both products are in the dotted area buy product 2, while those consumers for whom $\max \left\{\varepsilon_{1}, \varepsilon_{2}\right\}<p^{*}$ do not buy anything (the white rectangle in the bottom-left corner).

Next, suppose that the firm sets a small positive search cost $s_{2}\left(\operatorname{such}\right.$ that $\left.x_{2}>p^{*}\right)$ for product 2 but keeps charging $p^{*}$ for both goods, and that this is common knowledge. In these circumstances,

\footnotetext{
${ }^{7}$ In the online appendix, I follow Hagiu and Hałaburda (2014) and show that wary consumer beliefs lead to the same equilibrium. I use the assumption about passive beliefs for analytical tractability.

${ }^{8}$ The search cost $s_{1}$ has to be sufficiently small to ensure that $x_{1}-p_{1}^{*}=\max \left\{x_{i}-p_{i}^{*}\right\}_{i=1,2}$. Moreover, $s_{1}$ does not have any effect on the optimal prices and $s_{2}^{*}$.

${ }^{9}$ If $f(\varepsilon)$ is not log-concave, then the monopolist may choose different prices for symmetric products, e.g. Gamp (2016). A proof regarding the symmetric price $p^{*}$ can be found in the online appendix.
} 


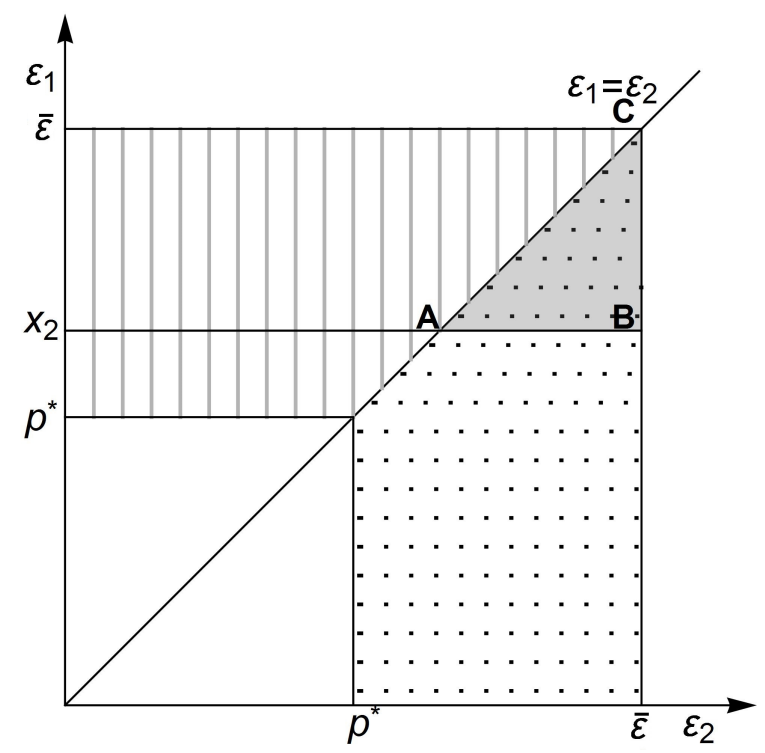

(a)

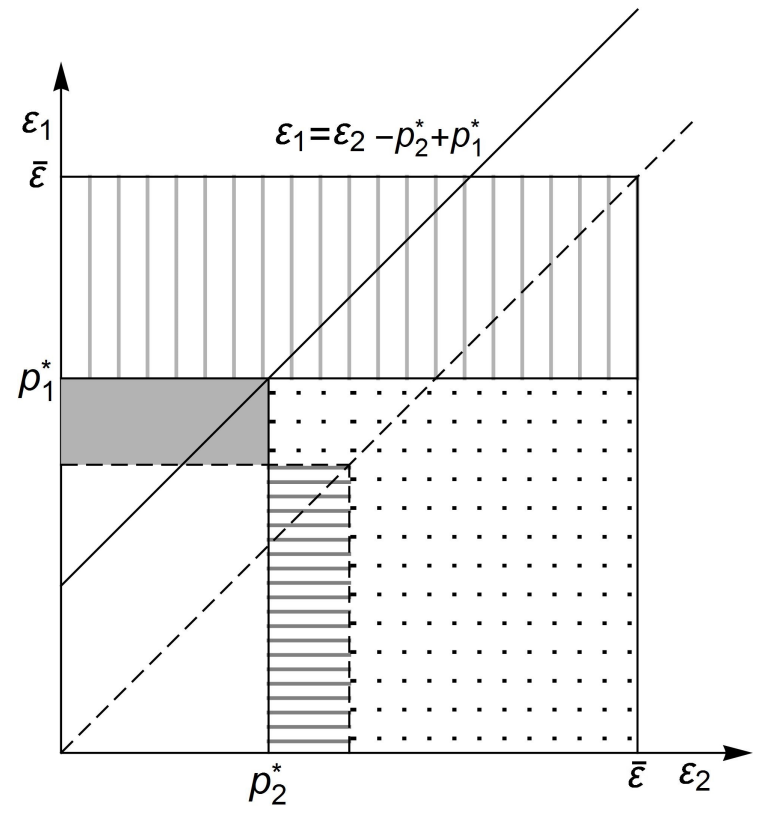

(b)

Figure 1: Consumer switching with obfuscation

consumers apply the optimal search and stopping rule. Given $s_{1}=0$ and $s_{2}>0$, all consumers first consider product 1 . The customers who learn that $\varepsilon_{1} \geq x_{2}$ terminate their search and buy the first product. Other consumers continue searching, and buy the product that is the best for them, if any. As a result, some of the consumers, who bought the second product before, switch to the first product. These buyers are depicted in the grey area in Figure 1a (triangle $A B C$ ). The total number of consumers who buy from the monopolist does not change. Thus, the firm does not lose any income by obfuscating the second product, and the search cost itself does not have any direct effect on the profit of the firm. However, the allocation of consumers between the two products changes, which prompts the monopolist to revise its prices. In particular, the average $\varepsilon_{1}$ of consumers who buy product 1 increases, and the average $\varepsilon_{2}$ of consumers who buy the second product decreases. To show this, I compare the average values of $\varepsilon_{1}$ of consumers who buy product 1 with and without obfuscation. When the monopolist does not obfuscate the average $\varepsilon_{1}$ of consumers who buy product 1 equals

$$
\frac{\int_{p^{*}}^{\bar{\varepsilon}} \varepsilon F(\varepsilon) d F(\varepsilon)}{\int_{p^{*}}^{\bar{\varepsilon}} F(\varepsilon) d F(\varepsilon)}=\frac{\int_{p^{*}}^{\bar{\varepsilon}} \varepsilon F(\varepsilon) d F(\varepsilon)}{\frac{1}{2}\left(1-F\left(p^{*}\right)^{2}\right)} .
$$

When the monopolist sets $s_{2}>0$, the average $\varepsilon_{1}$ of consumers who switch from product 2 to product 1 is

$$
\frac{\int_{x_{2}}^{\bar{\varepsilon}} \int_{x_{2}}^{\varepsilon_{2}} \varepsilon_{1} d F\left(\varepsilon_{1}\right) d F\left(\varepsilon_{2}\right)}{\int_{x_{2}}^{\bar{\varepsilon}} \int_{x_{2}}^{\varepsilon_{2}} d F\left(\varepsilon_{1}\right) d F\left(\varepsilon_{2}\right)}=\frac{\int_{x_{2}}^{\bar{\varepsilon}} \int_{x_{2}}^{\varepsilon_{2}} \varepsilon_{1} d F\left(\varepsilon_{1}\right) d F\left(\varepsilon_{2}\right)}{\frac{1}{2}\left(1-F\left(x_{2}\right)\right)^{2}} .
$$


The expression (3) is increasing in $x_{2} \cdot{ }^{10}$ If $x_{2}$ approaches $\bar{\varepsilon}$, then (3) approaches $\bar{\varepsilon}$, and it is greater than (2). As a result, the monopolist can always set a $s_{2}$ sufficiently small that (3) is greater than (2). Because (3) is greater than (2), the average $\varepsilon_{1}$ of consumers who buy product 1 under obfuscation is greater. By following a similar reasoning, one can prove that the mean of $\varepsilon_{2}$ of consumers who buy product 2 under obfuscation decreases. Thus, given a positive value of $s_{2}$, the monopolist finds it optimal to raise the price of product 1 and to lower the price of product 2.

Clearly, the new pair of prices leads to a higher profit, and the only question that remains to be answered is how high the search cost $s_{2}$ must be. For any given pair of prices, the search cost $s_{2}$ does not change the number of consumers who buy from the monopolist. If the price of product 1 is higher, then the monopolist wants to minimize the number of consumers who buy the second product. The highest value of $s_{2}$ that the monopolist can set without shutting down product 2 is such that the reservation utility of product 2 equals zero. In this case, consumers who sample product 2 either buy the product or leave the firm without buying anything. Therefore, the monopolist solves the following maximization problem (4).

$$
\max _{p_{1}, p_{2}} p_{1}\left(1-F\left(p_{1}\right)\right)+p_{2} F\left(p_{1}\right)\left(1-F\left(p_{2}\right)\right)
$$

Proposition 1. Suppose that the monopolist can obfuscate its second product by choosing $s_{2}$. Then, in equilibrium, the firm sets the search cost of the second product such that the reservation utility of the product equals zero $\left(x_{2}^{*}=p_{2}^{*}\right)$, the profit-maximizing prices $p_{1}^{*}$ and $p_{2}^{*}$ solve (4) and $p_{1}^{*}>p_{2}^{*}$. Consumer surplus is lower than in the setting where the monopolist does not obfuscate at all.

The monopolist extracts more consumer surplus from consumers who buy product 1 than absent obfuscation because $p_{1}^{*}>p^{*}{ }^{11}$ Although $p_{2}^{*}$ is lower than the symmetric equilibrium price $p^{*}$, consumer surplus is lower if the monopolist obfuscates. This happens because the surplus of consumers who buy the second product is cannibalized by the search cost: $\int_{p_{2}^{*}}^{\bar{\varepsilon}}\left(\varepsilon-p_{2}^{*}\right) d F(\varepsilon)=s_{2}^{*}$. How welfare changes after the monopolist starts obfuscating depends on four factors. Firstly, some consumers who continue buying buy product 1 although they like product 2 more. Secondly, some additional consumers leave the market without buying anything (grey rectangle in Figure 1b). Thirdly, there are consumers who start buying under obfuscation (horizontally-striped are in Figure 1b). Fourthly, $F\left(p_{1}^{*}\right)$ consumers pay search costs. The total match value of the new consumers is not sufficiently high to cover the total search costs, and welfare is lower under obfuscation. ${ }^{12}$

The price ranking in Proposition 1 is the opposite to the equilibrium price ranking when every product is sold by a different seller (as in Zhou (2011)). To explain the difference between the two 0 .

\footnotetext{
${ }^{10}$ Its derivative with respect to $x_{2}$ has the same sign as $f\left(x_{2}\right)\left(1-F\left(x_{2}\right)\right) \int_{x_{2}}^{\bar{\varepsilon}}\left(\int_{x_{2}}^{\varepsilon_{2}} \varepsilon d F\left(\varepsilon_{1}\right)-\frac{1}{2}\left(1-F\left(x_{2}\right)\right) x_{2}\right) d F\left(\varepsilon_{2}\right)>$

${ }^{11}$ The proof of this inequality is in Claim 4 in Appendix.

${ }^{12}$ Details are in the online appendix. Gamp (2016) shows that welfare may increase due to obfuscation when $f(\varepsilon)$ is non-log-concave. In that setting $p^{*}$ and $p_{1}^{*}$ are very close to each other, and $p_{2}^{*}$ is significantly less. Then the total match value of additional consumers surpasses all welfare loses due obfuscation.
} 
models, I use the terminology of Armstrong et al. (2009) to refer to different firms. In particular, the seller whose product is searched for first is said to be a 'prominent' firm, and the other firm is called a 'non-prominent' firm.

After the prominent firm slightly lowers its price in Zhou (2011), it stops many consumers from visiting its competitor. Thus, the demand of the prominent firm is relatively price elastic. In contrast, the non-prominent firm is visited by consumers who do not like the prominent product. Therefore, the demand of the non-prominent firm is less price elastic, and the price of the prominent firm is lower than that of the non-prominent firm in equilibrium. In contrast, the monopolist does not lose that much revenue from consumers who switch to the second product, as does the prominent firm. Therefore, the multiproduct seller is more concerned with the 'quality' of the buyers of the first product than with their quantity. Specifically, by setting $s_{2}>0$, the monopolist singles out, though not perfectly, the consumers who value the first product highly. Then the seller raises the price of this product. Meanwhile, the distribution of the valuations of consumers who search for the second product shifts towards lower match values, which creates incentives to lower the second price. $^{13}$

In Salop (1977), a multiproduct monopolist applies a somewhat similar pricing policy to that of Proposition 1. In particular, consumers differ in their search costs and willingness to pay for homogeneous products in that model, they observe one price quote for free, and must pay search costs to observe a second price. The search costs and willingness to pay of consumers are positively correlated. The monopolist exploits this fact and sets the price of the first product higher than that of the second. Then, in equilibrium, some consumers having high search costs and high willingness to pay buy a more expensive product without checking the second price, and consumers having lower search costs observe both prices and buy a cheaper product. ${ }^{14}$ In contrast in the present paper, the firm uses obfuscation to screen the preferences of consumers in terms of horizontal product differentiation, and there is no heterogeneity in the search costs of the customers.

Similar analysis applies when the seller supplies more than two products. The characterization of the equilibrium with obfuscation follows similar reasoning to the one with two products, and the details can be found in the online appendix. Here I provide a summary. If the monopolist sells $k>2$ products, the firm sets the search costs and the prices of its products in such a way that all consumers follow the same search order by starting with product 1 and ending with product $k$. The search costs increase and the prices decrease in the search order, and the reservation utility of every product is set equal to zero. In that equilibrium, consumers consider products myopically: they sample product 2 if they observe $\varepsilon_{1} \leq p_{1}^{*}$, they search for the utility of product 3 after finding $\varepsilon_{2} \leq p_{2}^{*}$, and so on. As a result, obfuscation brings about a similar mechanism of sorting consumers according to their valuations to that of Proposition 1. The only difference is that consumers self-select into $k$ groups

\footnotetext{
${ }^{13}$ Prices are decreasing in search order in Arbatskaya (2007). However, that result arises because consumers differ in search costs and firms being search later face more competition.

${ }^{14} \mathrm{~A}$ similar result was obtained by Hämäläinen (2017).
} 
instead of two.

\section{Asymmetric products}

When the match values of two products are distributed identically, the monopolist is indifferent to which product to obfuscate more. In the real world, product valuations are often distributed differently and have different profit margins, in which case firms have to make that decision. For instance, the consumers' valuations of new clothing and phone models are higher on average, and these products have higher profit margins. Correspondingly, sellers often put new models in areas where consumer traffic is the highest and the products can be observed easily. ${ }^{15}$ Additionally, more profitable dishes are put in the sections of menus to which customers look first by additionally highlighting the names of the dishes with different fonts and photos. ${ }^{16}$

In this section, I analyse the case where the distributions of the match values of the two products differ, but the production costs of the two goods are identical. In addition to the assumptions made in Section 2, I parametrize $F(\varepsilon)$ by $\beta$. The distribution function is continuous in $\beta$, and an increase in $\beta$ turns $F(\varepsilon ; \beta)$ clockwise around a particular point $\varepsilon^{*}$, which can be either equal to zero or strictly positive. ${ }^{17}$ If $\varepsilon^{*}=0$, then, after a rotation, the new distribution function dominates the previous one in the sense of first-order stochastic dominance. This type of rotation increases the share of consumers with high match values, which I interpret as an increase in the quality of a product. If $\varepsilon^{*}>0$, then, after a rotation, the tails of the density function $f(\varepsilon ; \beta)$ become thicker. As a result, both the share of consumers who like a product very much and the share of consumers who like it very little increase. ${ }^{18}$

If $\varepsilon^{*}>0$ and the lowest valuation by a consumer who buys a product in equilibrium is greater than $\varepsilon^{*}$, I refer to the product as a niche market product. This most often happens when product valuations are widely dispersed. If the lowest valuation by a consumer who buys a product in equilibrium is less than $\varepsilon^{*}$, the product is said to be a mass market product. The latter case most often happens when a sufficiently large mass of consumers is close to the mean of $\varepsilon$. It is important to observe here that by a rotation point of function $F(\varepsilon ; \beta)$, I refer to the crossing point of $F\left(\varepsilon ; \beta^{\prime}\right)$ and $F\left(\varepsilon ; \beta^{\prime \prime}\right)$, where $\beta^{\prime}-\beta^{\prime \prime} \rightarrow 0$, and it is not the crossing point of $F_{1}\left(\varepsilon ; \beta_{1}\right)$ and $F_{2}\left(\varepsilon ; \beta_{2}\right)$, where $\beta_{1} \gg \beta_{2}$. Actually, if $\beta_{1} \gg \beta_{2}$, the crossing point of $F_{1}\left(\varepsilon ; \beta_{1}\right)$ and $F_{2}\left(\varepsilon ; \beta_{2}\right)$ lies between the rotation points $\varepsilon_{1}^{*}$ and $\varepsilon_{2}^{*}$. By following Johnson and Myatt (2006), I assume that $\varepsilon^{*}>0$ does not move to the right when $\beta$ increases. Thus, if $\beta_{1}>\beta_{2}$, then $\varepsilon_{1}^{*} \leq \varepsilon_{2}^{*}$.

Additionally, I place one more restriction on the change in $f(\varepsilon ; \beta)$ with respect to $\beta$. More

\footnotetext{
${ }^{15}$ Michalowicz (2015) notes that "shoppers will pay attention to displays [just to the right of the door], and the displays should be stocked with high-profit goods".

${ }^{16}$ See Hullinger (2015); Kliever (2015) for examples.

${ }^{17}$ This method, employed to model ex ante product differentiation, is similar to the one presented by Johnson and Myatt (2006) and Bar-Isaac et al. (2012).

${ }^{18}$ Graphical examples of the rotations can be found in the online appendix in Figure 2.
} 
particularly, suppose that $F(\varepsilon ; \beta)$ decreases in the interval $\left[\varepsilon_{a}, \bar{\varepsilon}\right], \varepsilon_{a}>0$ after $\beta$ increases to $\beta^{\prime}$. In this interval, the density function $f(\varepsilon ; \beta)$ rotates counter-clockwise around some point $\varepsilon_{c} \in\left(\varepsilon_{a}, \bar{\varepsilon}\right)$, and I assume that $\partial\left(f\left(\varepsilon ; \beta^{\prime}\right) / f(\varepsilon ; \beta)\right) / \partial \varepsilon>0$. Namely, the functions $f\left(\varepsilon ; \beta^{\prime}\right)$ and $f(\varepsilon ; \beta)$ satisfy the monotone likelihood ratio property. This assumption is satisfied by many exponential family distribution functions, and a power distribution function.

\section{Vertical product differentiation}

I begin with vertically differentiated products and show that the monopolist obfuscates a lowerquality product in equilibrium. Suppose that product 1 is a higher-quality product $\left(\beta_{1}>\beta_{2}\right.$ and $\left.F_{2}\left(\varepsilon ; \beta_{2}\right)>F_{1}\left(\varepsilon ; \beta_{1}\right), \forall \varepsilon \in(0, \bar{\varepsilon})\right)$ and there is no obfuscation. In this instance, the profit-maximizing price of product 1 equals $p_{1}^{0}$, the profit-maximizing price of product 2 is $p_{2}^{0}$ and $p_{1}^{0} \geq p_{2}^{0}$. Further, I restrain the firm from changing the prices, but allow the use of a positive search cost for one of the two products. Clearly, the monopolist finds it profitable to obfuscate product 2 because the search cost increases the number of consumers buying product 1 and does not change the total number of purchases.

If the firm is allowed both to obfuscate and adjust its prices, then the price of a non-obfuscated product goes up and the price of the obfuscated product goes down. This happens irrespective of the order of $\beta$ s. However, the price of the non-obfuscated product increases more if its quality is higher. To show this, I denote the number of consumers who switch from product 2 to product 1 with obfuscation of product 2 by $n_{s 2}$. Similarly, the number of consumers who switch from product 1 to product 2 , when product 1 is obfuscated, is denoted by $n_{s 1}$. Because of the difference in distribution functions, $n_{2 s}$ is greater than $n_{s 1}$ : there are more consumers who draw high match values for product 1 than for product 2. Additionally, the mean $\varepsilon_{1}$ by $n_{s 2}$ consumers is greater than the mean $\varepsilon_{2}$ by $n_{s 1}$ consumers. As a result, the demand for product 1 is less price elastic, which allows raising the first price more. Because the obfuscation of product 2 leads to a higher profit margin for product 1 than the profit margin for product 2 when product 1 is obfuscated, obfuscating product 2 is more profitable. ${ }^{19}$

Proposition 2. Suppose that the monopolist sells two vertically differentiated products. Then, in equilibrium, the firm always obfuscates the lower-quality product by setting its reservation utility equal to zero.

Mussa and Rosen (1978) analyse a market in which the monopolist sells products that differ in quality, it is more expensive to produce a higher-quality product, and consumers differ in their valuations of quality. In that model, the firm reduces the quality of the product sold to consumers with lower valuations of quality to extract more consumer surplus from consumers who value quality

\footnotetext{
${ }^{19}$ Gamp (2016) shows that it depends on the properties of $f(\varepsilon ; \beta) / F(\varepsilon ; \beta)$ whether the monopolist obfuscates a higher- or a lower-quality product. This difference in results stems from the fact that Gamp (2016) allows changes in the support of $\varepsilon$ while rotating the distribution functions, but here, the support of the match value is strictly fixed.
} 
highly. In this paper, the obfuscation of a lower-quality product is a somewhat similar mechanism. In particular, the product that has a lower expected value is ex ante inferior, and the search cost decreases its ex ante utility even more. Therefore, the monopolist raises the price for buyers of the high-quality product, and in this way the firm extracts more consumer surplus.

\section{Mass and niche market products}

Whether the monopolist obfuscates the product with more or less dispersed match values depends on whether the goods are niche or mass market products. Suppose that both products are mass market products, product 2 is less so $\left(\beta_{2}>\beta_{1}\right)$, and there is no obfuscation. In this case, $p_{1}^{0}<p_{2}^{0}<\varepsilon_{2}^{*}$ and $F_{1}\left(p_{2}^{0} ; \beta_{1}\right)<F_{2}\left(p_{2}^{0} ; \beta_{2}\right)$. As a result, product 1 is as if a higher-quality product, and the monopolist chooses to obfuscate product 2 in equilibrium. Next, consider the case when both products are niche market products, and product 1 is less so $\left(\beta_{1}>\beta_{2}\right)$. Then, $p_{1}^{0}>p_{2}^{0}>\varepsilon_{2}^{*}$ and $F_{1}\left(p_{2}^{0} ; \beta_{1}\right)<F_{2}\left(p_{2}^{0} ; \beta_{2}\right)$. Again, product 1 is as if a higher-quality product, which makes obfuscating product 2 more profitable.

Proposition 3. Suppose that the multiproduct monopolist sells two products that differ in design. In this case:

a) if both goods are niche market products, then the monopolist obfuscates the product that is less so by setting its reservation utility equal to zero;

b) if both goods are mass market market products, then the monopolist obfuscates the product that is less so by setting its reservation utility equal to zero.

Proof. Similar to the proof of Proposition 2.

The decision of the monopolist as to which product to obfuscate, when one product is a niche market product and the other product is a mass market product, is more complicated because the prices of the two products are non-monotonic in the rotations of their distribution functions (as seen in Johnson and Myatt, 2006). However, by using the results of Propositions 2 and 3, I can provide the following discussion about the choice available to the monopolist.

Suppose that product 1 is a niche market product and product 2 is a mass market product $\left(\beta_{1}>\beta_{2}\right)$ and there is no obfuscation. Then the profit-maximizing prices are $p_{1}^{0}$ and $p_{2}^{0}$ for product 1 and product 2 . These prices lie between $\varepsilon_{1}^{*}$ and $\varepsilon_{2}^{*}$. I observe that the firm chooses to obfuscate product $i$ if $F_{i}\left(p ; \beta_{i}\right)>F_{j}\left(p ; \beta_{j}\right), i \neq j$. Thus, whether product 1 is obfuscated or product 2 is obfuscated in equilibrium depends on the positions of $p_{1}^{0}$ and $p_{2}^{0}$ relative to the crossing point of $F_{1}\left(\varepsilon ; \beta_{1}\right)$ and $F_{2}\left(\varepsilon ; \beta_{2}\right){ }^{20}$

\footnotetext{
${ }^{20}$ van Nierop et al. (2008) observe that supermarkets place bulk items that are often mass products on the bottom shelves, while the top shelves contain more specialty items (niche products). However, after running the optimization procedure, those authors find that sometimes the reallocation of products results in higher profit.
} 


\section{Robustness check}

In this section, I study the role of price observability and different marginal production costs on the equilibrium outcome. The analysis shows that the result of Proposition 1 often holds after altering a few assumptions of the main model.

\section{Observable prices}

Consider the setting of Section 2 and assume that consumers observe the prices of both goods but do not observe their match values of the second product without searching for it. In this instance, there is an additional effect of a deviation price $p_{2}$ that makes the demand for product 2 more elastic. In particular, if the monopolist lowers $p_{2}$, then not only do more consumers buy product 2 after observing it, but also more consumers search for the utility of product $2\left(x_{2}-p_{2}\right.$ becomes higher). Thus, the pricing externalities among the two products are stronger and the incentives to lower the second price are weaker. However, the monopolist obfuscates the second product by setting its reservation utility equal to zero and the prices that are specified in Proposition 1 in equilibrium. This happens because, similarly to the setting in Section 3, the monopolist wants to minimize the number of consumers who buy a product that is priced less. ${ }^{21}$

\section{Differences in production costs}

In this section, I study the set-up of Section 2 and additionally assume that the marginal production cost of product 2 is $c>0$, whereas the marginal production cost of product 1 is zero. The monopolist may obfuscate either product 1 or product 2 . In both cases, if the firm obfuscates, then it sets the reservation utility of the obfuscated product equal to zero. By doing this, the seller minimizes the number of consumers who buy a product with a lower profit margin.

If there is no obfuscation, the profit margin for product 2 is often lower. ${ }^{22}$ By keeping the same prices and obfuscating product 2, the firm would encourage more consumers to buy product 1 and its profit would be higher. Therefore, the monopolist obfuscates in equilibrium. When the firm obfuscates, the profit margin for its non-obfuscated product increases, and the profit margin for the obfuscated product decreases. The order of the products that is used in equilibrium is such that a non-obfuscated product has the highest possible profit margin. Thus, to find whether product 1 or product 2 is obfuscated in equilibrium, one needs to compare the profit margins for both products in both obfuscation orders. This task is complicated for general distribution functions. Therefore, I study a special case with a uniformly distributed $\varepsilon$ in Proposition 4 and rely on numerical simulations

\footnotetext{
${ }^{21}$ For an arbitrary $x_{2}>p_{2}$, the pay-off is not well-behaved in prices (it has kinks). See the online appendix for more details, as well as Gamp (2016).

${ }^{22}$ See some examples in the online appendix.
} 
for other distribution functions. I find that, in equilibrium, the firm chooses to obfuscate the product with positive marginal costs.

Proposition 4. Suppose that $\varepsilon$ is distributed uniformly in the interval $[0,1]$, and it costs $c \in(0 ; 1)$ to produce a unit of product 2 . Then, the monopolist obfuscates product 2 in equilibrium by setting its reservation utility equal to zero.

\section{Discussion}

This paper studies the incentives for the monopolist to use search costs to screen consumer preferences. The analysis shows that multiproduct firms may use obfuscation to induce consumer self-sorting according to their preferences and thereby earn higher profits by reducing consumer surplus. This study has covered several different model specifications such as differences in product quality and production costs. According to the results, incentives to obfuscate remain after slightly perturbing the basic monopoly model with symmetric products. Nevertheless, there are a few issues that are worth analysing further.

It has been assumed in the present paper that the match values of products are distributed independently. However, in the real world, the products of one seller may have similarities, e.g. computers that are produced by the same producer have similarities in design and functionality. When one match value carries information about other match values, the incentives employed by a consumer to search change. Suppose that the match values of the products are correlated negatively and a consumer draws a low match value of one product. In this example, the probability that the match value of another product is higher increases, which encourages the consumer to search more. In contrast, if the match value of the sampled product is high, then the consumer will want to search less. Then, if match values are correlated negatively, on average the valuations by consumers of products that are sampled and bought further up in the search order are higher. This creates incentives for a seller to increase the prices of the later sampled products, which might destroy the incentives to obfuscate. If the match values are correlated positively, then the expected gains form searching are lower, and so consumers are less willing to search. In that case, differences in prices have more influence on search intensity, and a firm may have stronger incentives to reduce the prices of products that are searched later. Thus, if match values are correlated positively, the pricing and obfuscation strategies of firms may be similar to those analysed in this paper.

Obfuscation is profitable in monopoly if intra-store search costs do not encourage consumers to go for their outside options by leaving obfuscated products unsearched. The same applies for a market with more multiproduct firms: it must be worthwhile for a consumer to search an obfuscated product instead of visiting other firms or leaving the market without any purchase. This happens if consumers pay positive search costs to visit each firm for the first time. ${ }^{23}$ In this case, a consumer

\footnotetext{
${ }^{23}$ There is an example of a duopoly in the online appendix.
} 
does not visit a firm if her highest observed utility is more than the reservation utility of the seller. As a result, a firm may introduce sufficiently small intra-store search costs such that the reservation utilities of its obfuscated products are greater than the reservation utilities of its competitors. This obfuscation strategy guarantees that a consumer inspect all product of the obfuscating seller before visiting other firms and the intra-store search costs allow consumer screening. Yet differently from monopoly, it is important for profitable obfuscation that actual prices are unobservable to consumers before paying costly visits to firms. Prices affect the search order inside a shop (like in monopoly) and determine in what order consumers visit firms. The second feature may be so important in oligopoly that sellers may set the prices of their less obfuscated products less than those of more obfuscated goods, which would render obfuscation unprofitable. As a result, it may be that in oligopoly with observable deviation prices firms either do not obfuscate in equilibrium or apply mixed pricing strategies similar to those in Armstrong and Zhou (2011).

Finally, consumers often differ in their characteristics, which leads to differences in search costs when the monopolist arranges its goods in a particular manner. In this instance, obfuscation may discourage some consumers from searching for the utility of an obfuscated product, and search costs would have a direct effect on the number of consumers who buy from the firm. It is very likely that in this case the monopolist would choose a lesser intensity of obfuscation, because of which the profit of the firm would increase less and consumer surplus would decrease less. 


\section{References}

Anagol, S., S. Cole, and S. Sarkar (2013, March 7). Understanding the advice of commissionsmotivated agents: Evidence from the indian life insurance market. HBS Working paper No. $12-055$.

Anderson, S. P. and R. Renault (1999). Pricing, product diversity, and search cost: a BertrandChamberlin-Diamond model. RAND Journal of Economics 30(4), 719-735.

Anderson, S. P. and R. Renault (2006). Advertising content. American Economic Review 96(1), 93-113.

Arbatskaya, M. (2007). Ordered search. RAND Journal of Economics 38(1), 119-126.

Armstrong, M., J. Vickers, and J. Zhou (2009). Prominence and consumer search. RAND Journal of Economics 40(2), 209-233.

Armstrong, M. and J. Zhou (2011). Paying for prominence. Economic Journal 121 (556), 368-395.

Bagnoli, M. and T. Bergstrom (2005). Log-concave probability and its applications. Economic Theory 26(2), 445-469.

Bar-Isaac, H., G. Caruana, and V. Cuñat (2012). Search, design, and market structure. American Economic Review 102(2), 1140-1160.

Bergstresser, D., J. M. R. Chalmers, and P. Tufano (2009). Assessing the costs and benefits of brokers in the mutual fund industry. Review of Financial Studies 22(10), 4129-4156.

Bulow, J. I. (1982). Durable-goods monopolists. Journal of Political Economy 90(2), 314-332.

Burguet, R., R. Caminal, and M. Ellman (2015). In Google we trust? International Journal of Industrial Organization 39, $44-55$.

Caminal, R. (1996). Price advertising and coupons in a monopoly market. Journal of Industrial Economics 44, 33-52.

Coase, R. H. (1972). Durability and monopoly. The Journal of Law E Economics 15(1), $143-149$.

Derbyshire, D. (2004). They have ways of making you spend. On the website of the Telegraph: http://www.telegraph.co.uk/culture/3634141/They-have-ways-of-making-you-spend.html. The website was accessed in Jun., 2016.

Dréze, X., S. J. Hoch, and M. E. Purk (1994). Shelf management and space elasticity. Journal of Retailing 70(4), 301-326. 
Ellison, G. and A. Wolitzky (2012). A search cost model of obfuscation. RAND Journal of Economics $43(3), 417-441$.

Gamp, T. (2016, June). Guided search.

Gu, Z. and Y. Liu (2013). Consumer fit search, retailer shelf layout, and channel interaction. Marketing Science 32(4), 652-668.

Hagiu, A. and H. Hałaburda (2014). Information and two-sided platform profits. International Journal of Industrial Organization 34, 25 - 35.

Hagiu, A. and B. Jullien (2011). Why do intermediaries divert search? RAND Journal of Economics 42(2), 337-362.

Hämäläinen, S. (2017, March). A micro foundation of obfuscation: time cost, strategic complexity and consumer deadlines.

Hullinger, J. (2015, April). 8 psychological tricks of restaurant menus. On the website of Mental Floss: http://mentalfloss.com/article/63443/8-psychological-tricks-restaurant-menus. The website was accessed in Mar., 2016.

Iyer, G. and D. Kuksov (2012). Competition in consumer shopping experience. Marketing Science $31(6), 913-933$.

Janssen, M. C. W. and M. C. Non (2009). Going where the ad leads you: On high advertised prices and searching where to buy. Marketing Science 28(1), 87-98.

Johnson, J. P. and D. P. Myatt (2006). On the simple economics of advertising, marketing, and product design. American Economic Review 96(3), 756-784.

Kliever, J. (2015, March). 10 menu design hacks restaurants use to make you order more. On the website of Canva: https://designschool.canva.com/blog/menu-psychology-design/. The website was accessed in Mar., 2016.

Mannino, N. (2012). Seven shopping secrets retailers won't tell you. On the website of Fox Business: http://www.foxbusiness.com/personal-finance/2011/04/22/ 7-shopping-secrets-retailers-wont-tell/\#ixzz2AdATb2lw. The website was accessed in Sept., 2016.

Michalowicz, M. (2015, February). A guide to store layouts that can increase sales. Available at https://www.americanexpress.com/us/small-business/openforum/articles/ the-blueprint-for-designing-the-perfect-store-for-more-sales/. The website was accessed in Nov. 2015. 
Mitford, J. (1963). The American Way of Death. Simon \& Schuster.

Mussa, M. and S. Rosen (1978). Monopoly and product quality. Journal of Economic Theory 18(2), $301-317$.

Perloff, J. M. and S. C. Salop (1985). Equilibrium with product differentiation. Review of Economic Studies 52(1), 107-120.

Rhodes, A. (2015). Multiproduct retailing. The Review of Economic Studies 82(1), 360 - 390.

Salop, S. (1977). The noisy monopolist: Imperfect information, price dispersion and price discrimination. The Review of Economic Studies 44(3), 393-406.

Shelegia, S. (2011). Multiproduct pricing in oligopoly. International Journal of Industrial Organization $30(2), 231-242$.

Stokey, N. (1979). Intertemporal price discrimination. Quarterly Journal of Economics 93(3), 355-371.

Stokey, N. L. (1981). Rational expectations and durable goods pricing. The Bell Journal of Economics 12(1), 112-128.

van Nierop, E., D. Fok, and P. H. Franses (2008). Interaction between shelf layout and marketing effectiveness and its impact on optimizing shelf arrangements. Marketing Science 27(6), 10651082.

Wang, C. (2017). Advertising as a search deterrent. RAND Journal of EeEconomics. forthcoming.

Weitzman, M. L. (1979). Optimal search for the best alternative. Econometrica 47(3), 641-654.

White, A. (2013). Search engines: Left side quality versus right side profits. International Journal of Industrial Organization 31(6), 690 - 701.

Wilson, C. M. (2010). Ordered search and equilibrium obfuscation. International Journal of Industrial Organization 28(5), 496-506.

Wolinsky, A. (1986). True monopolistic competition as a result of imperfect information. Quarterly Journal of Economics 101 (3), 493-512.

Zhou, J. (2009, April). Prominence in search markets: Competitive pricing and central pricing.

Zhou, J. (2011). Ordered search in differentiated markets. International Journal of Industrial Organization 29(2), 253-262.

Zhou, J. (2014). Multiproduct search and the joint search effect. American Economic Review 104(9), 2918-2939. 


\section{Appendix}

Proof of proposition 1. The proof of the proposition consists of three parts. In Part I, I derive the pay-off of the monopolist that sets a positive $s_{2}$, and $p_{1}$ and $p_{2}$ are such that $x_{2}-p_{2}^{*}+$ $\max \left\{p_{1}, p_{2}\right\} \leq \bar{\varepsilon}$. It is shown that $x_{2}^{*}=p_{2}^{*}$ in Part II. Additionally, there are three claims showing that the pair $\left\{p_{2}^{*}, p_{1}^{*}\right\}$ is unique, $p_{2}^{*}<p_{1}^{*}$ and the pay-off of the monopolist is locally concave. The incentives to deviate to higher prices are checked in Part III.

Part I. After entering the shop, a consumer observes $\varepsilon_{1}-p_{1}$. The customer terminates searching and buys product 1 if $\varepsilon_{1}-p_{1} \geq x_{2}-p_{2}^{*}$, and searches for the utility of the second product if the inequality is reversed. The probability of the first event is $1-F\left(x_{2}-p_{2}^{*}+p_{1}\right)$. After observing both prices and match values, the consumer may still buy the first product. This happens if $\varepsilon_{1}-p_{1} \geq$ $\max \left\{\varepsilon_{2}-p_{2}, 0\right\}$. The probability of this event is

$$
\int_{p_{1}}^{x_{2}-p_{2}^{*}+p_{1}} F\left(\varepsilon-p_{2}+p_{1}\right) d F(\varepsilon)
$$

As a result, demand for product 1 equals

$$
d_{1}\left(p_{1}, p_{2}, x_{2}\right)=1-F\left(x_{2}-p_{2}^{*}+p_{1}\right)+\int_{p_{1}}^{x_{2}-p_{2}^{*}+p_{1}} F\left(\varepsilon-p_{1}+p_{2}\right) d F(\varepsilon) .
$$

A consumer buys product 2 conditional on searching for its utility. The search happens if $\varepsilon_{1}-p_{1}<x_{2}-p_{2}^{*}$. The customer buys product 2 if $\varepsilon_{2}-p_{2}>\max \left\{\varepsilon_{1}-p_{1}, 0\right\}$. The probability of these two events gives the demand for product 2 , which equals

$$
d_{2}\left(p_{1}, p_{2}, x_{2}\right)=F\left(x_{2}-p_{2}^{*}+p_{1}\right)\left(1-F\left(x_{2}-p_{2}^{*}+p_{2}\right)\right)+\int_{p_{2}}^{x_{2}-p_{2}^{*}+p_{2}} F\left(\varepsilon-p_{2}+p_{1}\right) d F(\varepsilon) .
$$

The pay-off of the monopolist equates to the total revenue from selling both products:

$$
\pi\left(p_{1}, p_{2}, x_{2}\right)=p_{1} d_{1}\left(p_{1}, p_{2}, x_{2}\right)+p_{2} d_{2}\left(p_{1}, p_{2}, x_{2}\right)
$$

The profit-maximizing $x_{2}$ is a corner solution because the derivative of $\pi\left(p_{1}, p_{2}, x_{2}\right)$ with respect to $x_{2}$ does not equal zero:

$$
\left.\frac{\partial \pi\left(p_{1}, p_{2}, x_{2}\right)}{\partial x_{2}}\right|_{\boldsymbol{p}=\boldsymbol{p}^{*} x_{2}=x_{2}^{*}}=\left(p_{1}^{*}-p_{2}^{*}\right) f\left(x_{2}^{*}-p_{2}^{*}+p_{1}^{*}\right)\left(F\left(x_{2}^{*}\right)-1\right) .
$$

Part II. Because (5) leads to a corner solution, the optimal $x_{2}^{*}$ equals either $p_{2}^{*}$ or $\bar{\varepsilon}$. In the second case, because both products are symmetric, both prices are equal: $p_{1}^{*}=p_{2}^{*}=p^{*}$. In the first case, it must be that $p_{1}^{*}>p_{2}^{*}$. Further in the proof, I use three claims. Firstly, I show that if $x_{2}=p_{2}^{*}$, then 
there is a unique pair $\left\{p_{1}^{*}, p_{2}^{*}\right\}$ that solves the system of two first-order conditions with respect to both prices, and $p_{1}^{*}>p_{2}^{*}$. Secondly, I demonstrate that pay-off function of the monopolist is locally concave at this point. Finally, I show that the profit with $x_{2}=p_{2}^{*}$ is greater than by setting $x_{2}=\bar{\varepsilon}$.

Claim 1. If $x_{2}^{*}=p_{2}^{*}$, then there is a unique pair $\left\{p_{1}^{*}, p_{2}^{*}\right\}$ that solves the system of the two first-order conditions with respect to $p_{1}$ and $p_{2}$, and $p_{1}^{*}>p_{2}^{*}$.

Proof. If $x_{2}=p_{2}^{*}$, then the system of the first-order conditions with respect to both prices are

$$
1-F\left(p_{1}^{*}\right)-\left(p_{1}^{*}-p_{2}^{*}\right) f\left(p_{1}^{*}\right)\left(1-F\left(p_{2}^{*}\right)\right)-p_{1}^{*} F\left(p_{2}^{*}\right) f\left(p_{1}^{*}\right)=0
$$

and

$$
F\left(p_{1}^{*}\right)\left(1-F\left(p_{2}^{*}\right)-p_{2}^{*} f\left(p_{2}^{*}\right)\right)=0 .
$$

I divide equation (7) by $f\left(p_{2}^{*}\right) F\left(p_{1}^{*}\right)$ and obtain equation (8). After dividing equation (6) by $f\left(p_{1}^{*}\right)$, I obtain equation (9).

$$
\begin{gathered}
\frac{1-F\left(p_{2}^{*}\right)}{f\left(p_{2}^{*}\right)}-p_{2}^{*}=0 \\
\frac{1-F\left(p_{1}^{*}\right)}{f\left(p_{1}^{*}\right)}-\left(p_{1}^{*}-p_{2}^{*}\right)\left(1-F\left(p_{2}^{*}\right)\right)-p_{1}^{*} F\left(p_{2}^{*}\right)=0
\end{gathered}
$$

Because $f(\varepsilon)$ is log-concave, the ratio $(1-F(\varepsilon)) / f(\varepsilon)$ is decreasing in $\varepsilon$ (see Bagnoli and Bergstrom (2005)). As a result, the the left-hand-side (LHS) of (8) is decreasing in $p_{2}^{*}$ and the LHS of (9) is decreasing in $p_{1}^{*}$. If $p_{2}^{*}=0$, then the LHS of (8) is positive. If $p_{2}^{*}=\bar{\varepsilon}$, the LHS of (8) is negative. Thus, there is a unique $p_{2}^{*}$ that solves (8). Similarly, if $p_{1}^{*}=0$, then the LHS of (9) is positive. If $p_{1}^{*}=\bar{\varepsilon}$, then the LHS of (9) is negative. Thus, there is a unique $p_{1}^{*}$ that solves (9) for given $p_{2}^{*}$.

Finally, I prove that $p_{1}^{*}>p_{2}^{*}$. Suppose that it is the opposite: $p_{1}^{*} \leq p_{2}^{*}$. Because (9) is decreasing in $p_{1}^{*}$, it must be true that

$$
\frac{1-F\left(p_{2}^{*}\right)}{f\left(p_{2}^{*}\right)}-\left(p_{2}^{*}-p_{2}^{*}\right)\left(1-F\left(p_{2}^{*}\right)\right)-p_{2}^{*} F\left(p_{2}^{*}\right)=\frac{1-F\left(p_{2}^{*}\right)}{f\left(p_{2}^{*}\right)}-p_{2}^{*} F\left(p_{2}^{*}\right) \leq 0 .
$$

By using (8), I conclude that (10) does not hold. Therefore, $p_{1}^{*}>p_{2}^{*}$.

Claim 2. If $x_{2}^{*}=p_{2}^{*}$, then the pay-off function of the monopolist is locally concave.

Proof. At the point where $x_{2}=p_{2}^{*}, p_{1}=p_{1}^{*}$ and $p_{2}=p_{2}^{*}$, the diagonal elements of the Hessian matrix $\mathcal{H}$ are 


$$
\mathcal{H}_{11}=\left.\frac{\partial^{2} \pi}{\partial p_{1}^{2}}\right|_{p=p^{*}, x_{2}=p_{2}^{*}}=-f^{\prime}\left(p_{1}^{*}\right)\left(\frac{2 f\left(p_{1}^{*}\right)}{f^{\prime}\left(p_{1}^{*}\right)}+p_{1}^{*}-p_{2}^{*}\left(1-F\left(p_{2}^{*}\right)\right)\right)
$$

and

$$
\mathcal{H}_{22}=\left.\frac{\partial^{2} \pi}{\partial p_{2}^{2}}\right|_{p=p^{*}, x_{2}=p_{2}^{*}}=-2 F\left(p_{1}^{*}\right) f\left(p_{2}^{*}\right)-p_{2}^{*} F\left(p_{1}^{*}\right) f^{\prime}\left(p_{2}^{*}\right)
$$

By using (9), I replace $p_{2}^{*}\left(1-F\left(p_{2}^{*}\right)\right)$ with $p_{1}^{*}-\frac{1-F\left(p_{1}^{*}\right)}{f\left(p_{1}^{*}\right)}$ and obtain (13).

$$
\mathcal{H}_{11}=-\frac{1}{f\left(p_{1}^{*}\right)}\left(2 f^{2}\left(p_{1}^{*}\right)+f^{\prime}\left(p_{1}^{*}\right)\left(1-F\left(p_{1}^{*}\right)\right)\right)<0
$$

By using (8), I rewrite (12) as (14), which is negative

$$
-F\left(p_{1}^{*}\right)\left(2 f\left(p_{2}^{*}\right)+\frac{1-F\left(p_{2}^{*}\right)}{f\left(p_{2}^{*}\right)} f^{\prime}\left(p_{2}^{*}\right)\right)=-\frac{F\left(p_{1}^{*}\right)}{f\left(p_{2}^{*}\right)}\left(2 f\left(p_{2}^{*}\right)^{2}+f^{\prime}\left(p_{2}^{*}\right)\left(1-F\left(p_{2}^{*}\right)\right)\right)<0 .
$$

The off-diagonal elements of the Hessian equal zero:

$$
\begin{aligned}
& \mathcal{H}_{12}=\left.\frac{\partial^{2} \pi}{\partial p_{1} \partial p_{2}}\right|_{p=\boldsymbol{p}^{*}, x_{2}=x_{2}^{*}}=f\left(p_{1}^{*}\right)\left(1-F\left(p_{2}^{*}\right)-f\left(p_{2}^{*}\right) p_{2}^{*}\right)=0, \\
& \mathcal{H}_{21}=\left.\frac{\partial^{2} \pi}{\partial p_{2} \partial p_{1}}\right|_{p=\boldsymbol{p}^{*}, x_{2}=x_{2}^{*}}=f\left(p_{1}^{*}\right)\left(1-F\left(p_{2}^{*}\right)-f\left(p_{2}^{*}\right) p_{2}^{*}\right)=0 .
\end{aligned}
$$

Hence, the determinant of the Hessian matrix is positive, and the pay-off function is locally concave in prices.

Claim 3. By setting $p_{1}=p_{1}^{*}>p_{2}=p_{2}^{*}$ and $x_{2}=p_{2}^{*}$, the monopolist earns more than by not obfuscating at all.

Proof. If the monopolist does not obfuscate at all, then the firm sets the same price for both products that equals

$$
p^{*}=\arg \max _{p} p\left(1-F(p)^{2}\right)
$$

and earns $\pi^{0}=p^{*}\left(1-F\left(p^{*}\right)^{2}\right)$.

The firm would earn the same profit if it charged the same price $p^{*}$ for both products and obfuscated its second product by setting a search cost $s$ such that $x_{2}^{*}=p^{*}$. In this case, the consumers who observed $\varepsilon_{1} \geq p^{*}$ would buy the first product, and the rest would search for the utility of the second product. After searching the consumers would buy the second product if $\varepsilon_{2} \geq p^{*}$, and they 
would buy nothing otherwise. Then the pay-off of the monopolist would be

$$
p^{*}\left(1-F\left(p^{*}\right)\right)+p^{*} F\left(p^{*}\right)\left(1-F\left(p^{*}\right)\right)=\pi^{0} .
$$

Consider the following artificial set-up. The monopolist obfuscates the match value of the second product and makes both prices observable. Additionally, the firm commits to set the search cost of the second product such that $x_{2}=p_{2}$. I denote the pay-off of the monopolist by $\pi^{a}$ in this setting. The prices of the products are $p_{1}^{a}$ and $p_{2}^{a}$. Then

$$
\pi_{a}=p_{1}^{a}\left(1-F\left(p_{1}^{a}\right)\right)+p_{2}^{a} F\left(p_{1}^{a}\right)\left(1-F\left(p_{2}^{a}\right)\right) .
$$

The first-order conditions with respect to both prices $p_{1}^{a}$ and $p_{2}^{a}$ give the same solution as (6)-(7). Thus, $p_{1}^{a}=p_{1}^{*} \neq p^{*}$ and $p_{2}^{a}=p_{2}^{*} \neq p^{*}$. As a result, I conclude that $\pi^{0}<\pi^{*}$, where

$$
\pi^{*}=p_{1}^{*}\left(1-F\left(p_{1}^{*}\right)\right)+p_{2}^{*} F\left(p_{1}^{*}\right)\left(1-F\left(p_{2}^{*}\right)\right)
$$

Part III. Large deviations. In the derivations of $d_{1}\left(p_{1}, p_{2}, x_{2}\right)$ and $d_{2}\left(p_{1}, p_{2}, x_{2}\right)$, I considered small local deviations. Any deviation in $s_{2}$ that ensures $x_{2}-p_{2}^{*} \geq 0$ does not change the derived demand functions. The same holds for any $p_{2} \leq \bar{\varepsilon}-x_{2}+p_{2}^{*}$ and $p_{1} \leq \bar{\varepsilon}-x_{2}+p_{2}^{*}$.

Consider $p_{1}>\bar{\varepsilon}-x_{2}+p_{2}^{*}, x_{2}-p_{2}^{*} \geq 0$ and any $p_{2} \neq p_{2}^{*}$. In this case, all consumers search for the utility of product 2 , and the pay-off of the monopolist is identical to the pay-off when $s_{2}=0$. The maximum of this pay-off is where $p_{2}=p_{1}=p^{*}$, and I conclude that this deviation is unprofitable by using Claim 3.

Next, suppose that the monopolist sets $p_{1} \leq \bar{\varepsilon}-x_{2}+p_{2}^{*}, x_{2}-p_{2}^{*} \geq 0$ and $p_{2}>\bar{\varepsilon}-x_{2}+p_{2}^{*}$. Then, the demand for product 1 is

$$
\begin{array}{r}
1-F\left(x_{2}-p_{2}^{*}+p_{1}\right)+\int_{\bar{\varepsilon}-p_{2}+p_{1}}^{x_{2}-p_{2}^{*}+p_{1}} d F(\varepsilon)+\int_{p_{1}}^{\bar{\varepsilon}-p_{2}+p_{1}} F\left(\varepsilon-p_{1}+p_{2}\right) d F(\varepsilon)= \\
1-F\left(\bar{\varepsilon}-p_{2}+p_{1}\right)+\int_{p_{1}}^{\bar{\varepsilon}-p_{2}+p_{1}} F\left(\varepsilon-p_{1}+p_{2}\right) d F(\varepsilon),
\end{array}
$$

and the demand for product 2 equals $\int_{p_{2}}^{\bar{\varepsilon}} F\left(\varepsilon-p_{2}+p_{1}\right) d F(\varepsilon)$. As a result, I again obtain the pay-off of the monopolist as if $s_{2}$ equalled zero. As a result, I rule out this deviation by using above written arguments.

The last large deviation is related to $s_{2}$ such that $x_{2}<p_{2}^{*}$. In this case, no consumer would search for the utility of product 2. Because the profit of a single-product monopolist is lower than the profit of a multiproduct monopolist, I rule out this deviation as well. 
Claim 4. Consumer surplus and total welfare are lower if the monopolist obfuscates.

Proof. If the monopolist does not obfuscate and charges $p^{*}$ for both products, then consumer surplus is

$$
C S^{0}=2 \int_{p^{*}}^{\bar{\varepsilon}}\left(\varepsilon-p^{*}\right) F(\varepsilon) d F(\varepsilon)
$$

Consider an artificial situation, where the monopolist sets the same price $p^{*}$ for both its products and obfuscates the second product by setting $x_{2}=p^{*}$. Then, consumer surplus equals the surplus of consumers who buy the non-obfuscated product, i.e.

$$
C S^{a}=\int_{p^{*}}^{\bar{\varepsilon}}\left(\varepsilon-p^{*}\right) d F(\varepsilon)
$$

The difference $C S^{0}-C S^{a}$ is positive because $\int_{p^{*}}^{\bar{\varepsilon}}\left(\varepsilon-p^{*}\right)(2 F(\varepsilon)-1) d F(\varepsilon)$ is decreasing in $p^{*}$ and equals 0 , when $p^{*}=\bar{\varepsilon}$.

Next, I prove that the price $p_{1}^{*}$ is greater than $p^{*}$. I use equation (9). It has been shown that the LHS of the equation is decreasing in $p_{1}^{*}$. Because $p_{2}^{*}=\arg \max _{p} p(1-F(p))$, the LHS of $(9)$ is increasing in $p_{2}$ for small values of $p_{2}$ and is decreasing for high values of $p_{2}$. Therefore, the implicit function $p_{1}\left(p_{2}\right)$ that is obtained from (9) is increasing in $p_{2}$ for all $p_{2}<p_{2}^{*}$ and is decreasing later. By additionally using the fact that $p_{2}^{*}<p_{1}^{*}$, I conclude that $p_{1}^{*}>p_{1}(\tilde{p})=\tilde{p}$, where $\tilde{p}$ is the price that solves (9) when $p_{1}^{*}=p_{2}^{*}=\tilde{p}$.

The price $\tilde{p}$ is a unique solution of (15), and $p^{*}$ solves (16).

$$
\begin{gathered}
\frac{1-F(\tilde{p})}{f(\tilde{p})}-\tilde{p} F(\tilde{p})=0 \\
\frac{1-F\left(p^{*}\right)^{2}}{f\left(p^{*}\right)}-2 F\left(p^{*}\right) p^{*}=0
\end{gathered}
$$

Furthermore, the LHS of (15) is decreasing in $\tilde{p}$ and

$$
\frac{1-F\left(p^{*}\right)^{2}}{f\left(p^{*}\right)}-2 F\left(p^{*}\right) p^{*}-\frac{1-F\left(p^{*}\right)}{f\left(p^{*}\right)}+F\left(p^{*}\right) p^{*}=\frac{F\left(p^{*}\right)}{f\left(p^{*}\right)}\left(1-F\left(p^{*}\right)-f\left(p^{*}\right) p^{*}\right)<0 .
$$

As a result, I conclude that $\tilde{p}>p^{*}$, which implies that $p_{1}^{*}>p^{*}$.

Consumer surplus when the monopolist obfuscates is

$$
C S^{*}=\int_{p_{1}^{*}}^{\bar{\varepsilon}}\left(\varepsilon-p_{1}^{*}\right) d F(\varepsilon)
$$

Because $p_{1}^{*}>p^{*}$, I obtain that $C S^{*}<C S^{a}$. Thus $C S^{*}<C S^{0}$.

Proof of proposition 2. In the proof, I assume that the first product is a higher-quality item $\left(\beta_{2}<\beta_{1}\right)$, and I show that the monopolist earns more by obfuscating the second product than the 
first product. To save space further in the proof, I omit $\beta_{i}$ from $F_{i}\left(\varepsilon ; \beta_{i}\right)$ and $f_{i}\left(\varepsilon ; \beta_{i}\right)$. Before proceeding with the proof of the proposition, I prove a claim that will be used in the proof.

Claim 5. Suppose that initially $\beta_{1}=\beta_{2}=\beta, \beta_{1}$ increases to $\beta^{\prime}>\beta$ and $\beta_{2}=\beta$. Then, in equilibrium the monopolist sets $x_{2}=p_{2}^{*}, p_{1}^{*}$ increases, $p_{2}^{*}$ does not change, and the profit of the firm increases.

Proof. The first-order conditions of the monopolist with respect to both prices are $\left(\Delta_{p}^{*}=p_{2}^{*}-p_{1}^{*}\right)$

$$
\begin{gathered}
1-F_{1}\left(x_{2}^{*}-\Delta_{p}^{*}\right)+\int_{p_{1}^{*}}^{x_{2}^{*}-\Delta_{p}^{*}} F_{2}\left(\varepsilon+\Delta_{p}^{*}\right) d F_{1}(\varepsilon)+\Delta_{p}^{*} f_{1}\left(x_{2}^{*}-\Delta_{p}^{*}\right)\left(1-F_{2}\left(x_{2}^{*}\right)\right)+ \\
\Delta_{p}^{*} \int_{p_{1}^{*}}^{x_{2}^{*}-\Delta_{p}^{*}} f_{2}\left(\varepsilon+\Delta_{p}^{*}\right) d F_{1}(\varepsilon)-p_{1}^{*} F_{2}\left(p_{2}^{*}\right) f_{1}\left(p_{1}^{*}\right)=0
\end{gathered}
$$

and

$$
\begin{gathered}
F_{1}\left(x_{2}^{*}-\Delta_{p}^{*}\right)\left(1-F_{2}\left(x_{2}^{*}\right)\right)+\int_{p_{2}^{*}}^{x_{2}^{*}} F_{1}\left(\varepsilon-\Delta_{p}^{*}\right) d F_{2}(\varepsilon)- \\
\Delta_{p}^{*} \int_{p_{2}^{*}}^{x_{2}^{*}} f_{1}\left(\varepsilon-\Delta_{p}^{*}\right) d F_{2}(\varepsilon)-p_{2}^{*} F_{1}\left(p_{1}^{*}\right) f_{2}\left(p_{2}^{*}\right)=0 .
\end{gathered}
$$

Similarly to the case in Section 3, the optimal value of $x_{2}$ is a corner solution because

$$
\frac{\partial \pi}{\partial x_{2}}=\Delta_{p}^{*} f_{1}\left(x_{2}^{*}-\Delta_{p}^{*}\right)\left(1-F_{2}\left(x_{2}^{*}\right)\right) \neq 0 .
$$

From (19) is it clear that if $p_{1}^{*}>p_{2}^{*}\left(\Delta_{p}^{*}<0\right)$, then the equilibrium where $x_{2}^{*}=p_{2}^{*}$ survives after the change in $\beta_{1}$. In what follows, I show that the difference $p_{1}^{*}-p_{2}^{*}$ is increasing in $\beta_{1}$ if $x_{2}^{*} \rightarrow p_{2}^{*}$. In turn, this implies that in equilibrium $x_{2}^{*}=p_{2}^{*}$ when $\beta_{1}$ increases.

I take the derivatives of the first-order conditions (17) and (18) with respect to both prices and $\beta_{1}$ and take their limits when $x_{2} \rightarrow p_{2}^{*}$. I label the LHS of $(17) H\left(p_{1}^{*}, p_{2}^{*}\right)$, and the LHS of (18) is

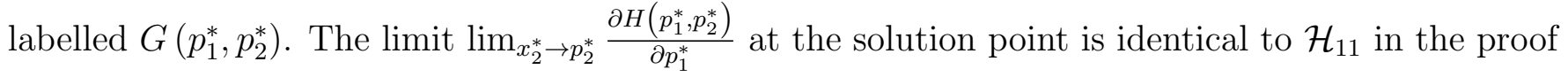
of Claim 2, which is negative.

$$
\lim _{x_{2}^{*} \rightarrow p_{2}^{*}} \frac{\partial H}{\partial p_{2}^{*}}=2 f_{1}\left(p_{1}^{*}\right)\left(1-F_{2}\left(p_{2}^{*}\right)\right)+\left(p_{1}^{*}-p_{2}^{*}\right) f_{1}^{\prime}\left(p_{1}^{*}\right)\left(1-F_{2}\left(p_{2}^{*}\right)\right)-p_{2}^{*} f_{2}\left(p_{2}^{*}\right) f_{1}\left(p_{1}^{*}\right)
$$

By using the first-order condition (18) on the limit $x_{2} \rightarrow p_{2}^{*}$, I obtain that $p_{2}^{*} f_{2}\left(p_{2}^{*}\right)=1-F_{2}\left(p_{2}^{*}\right)$ and the derivative simplifies to

$$
\lim _{x_{2}^{*} \rightarrow p_{2}^{*}} \frac{\partial H}{\partial p_{2}^{*}}=\left(1-F_{2}\left(p_{2}^{*}\right)\right) f_{1}\left(p_{1}^{*}\right)\left(1+\left(p_{1}^{*}-p_{2}^{*}\right) \frac{f_{1}^{\prime}\left(p_{1}^{*}\right)}{f_{1}\left(p_{1}^{*}\right)}\right)
$$


If $f_{1}^{\prime}\left(p_{1}^{*}\right) \geq 0$, then $(20)$ is positive.

Now I prove that $(20)$ is positive even if $f_{1}^{\prime}\left(p_{1}^{*}\right)<0$. By using (17) when $x_{2}^{*} \rightarrow p_{2}^{*}$, I obtain $(21)$.

$$
1+\left(p_{1}^{*}-p_{2}^{*}\right) \frac{f_{1}^{\prime}\left(p_{1}^{*}\right)}{f_{1}\left(p_{1}^{*}\right)}=1+\frac{f_{1}^{\prime}\left(p_{1}^{*}\right)}{f_{1}\left(p_{1}^{*}\right)}\left(\frac{1-F_{1}\left(p_{1}^{*}\right)}{f_{1}\left(p_{1}^{*}\right)}-p_{2}^{*} F_{2}\left(p_{2}^{*}\right)\right)
$$

Because $f_{1}^{\prime}\left(p_{1}^{*}\right)<0,(21)$ is increasing in $p_{2}^{*}$. Thus, the right-hand-side (RHS) of (21) is greater than

$$
1+\frac{f_{1}^{\prime}\left(p_{1}^{*}\right)}{f_{1}\left(p_{1}^{*}\right)} \frac{1-F_{1}\left(p_{1}^{*}\right)}{f_{1}\left(p_{1}^{*}\right)}=\frac{f_{1}^{2}\left(p_{1}^{*}\right)+f_{1}^{\prime}\left(p_{1}^{*}\right)\left(1-F_{1}\left(p_{1}^{*}\right)\right)}{f_{1}^{2}\left(p_{1}^{*}\right)}>0 .
$$

Hence, $\lim _{x_{2}^{*} \rightarrow p_{2}^{*}} \frac{\partial H}{\partial p_{2}^{*}}>0$.

$$
\lim _{x_{2}^{*} \rightarrow p_{2}^{*}} \frac{\partial H}{\partial \beta_{1}}=-\frac{\partial F_{1}\left(p_{1}^{*}\right)}{\partial \beta_{1}}+p_{2}^{*} \frac{\partial f_{1}\left(p_{1}^{*}\right)}{\partial \beta_{1}}\left(1-F_{2}\left(p_{2}^{*}\right)\right)-p_{1}^{*} \frac{\partial f_{1}\left(p_{1}^{*}\right)}{\partial \beta_{1}}
$$

Suppose that $\partial f_{1}\left(p_{1}^{*}\right) / \partial \beta_{1} \leq 0$, then because $p_{1}^{*}>p_{2}^{*}\left(1-F_{2}\left(p_{2}^{*}\right)\right)$ the derivative $\lim _{x_{2} \rightarrow p_{2}^{*}} \frac{\partial H}{\partial \beta_{1}}$ is positive. Next, I prove that if $\partial f_{1}\left(p_{1}^{*}\right) / \partial \beta_{1}>0$, then $\lim _{x_{2}^{*} \rightarrow p_{2}^{*}} \frac{\partial H}{\partial \beta_{1}}$ is also positive. To prove this, I use $\lim _{x_{2}^{*} \rightarrow p_{2}^{*}} H$ and replace $p_{2}^{*}\left(1-F_{2}\left(p_{2}^{*}\right)\right)-p_{1}^{*}$ with $-\left(1-F_{1}\left(p_{1}^{*}\right)\right) / f_{1}\left(p_{1}^{*}\right)$, and obtain $(22)$.

$$
\lim _{x_{2}^{*} \rightarrow p_{2}^{*}} \frac{\partial H}{\partial \beta_{1}}=-\frac{1}{f_{1}\left(p_{1}^{*}\right)}\left(\frac{\partial F_{1}\left(p_{1}^{*}\right)}{\partial \beta_{1}} f_{1}\left(p_{1}^{*}\right)+\left(1-F_{1}\left(p_{1}^{*}\right)\right) \frac{\partial f_{1}\left(p_{1}^{*}\right)}{\partial \beta_{1}}\right)
$$

Because $f(\varepsilon)$ satisfies the monotone likelihood ratio property when $F(\varepsilon)$ decreases, the ratio $f_{1}(\varepsilon) /\left(1-F_{1}(\varepsilon)\right)$ is decreasing in $\beta_{1}$. This implies that

$$
\frac{1}{\left(1-F_{1}(\varepsilon)\right)^{2}}\left(\frac{\partial f_{1}(\varepsilon)}{\partial \beta_{1}}\left(1-F_{1}(\varepsilon)\right)+f_{1}\left(\varepsilon_{1}\right) \frac{\partial F_{1}(\varepsilon)}{\partial \beta_{1}}\right)<0 .
$$

By using the last inequality, I conclude that (22) is positive.

Next, I take the derivatives of the second first-order condition. $\lim _{x_{2}^{*} \rightarrow p_{2}^{*}} \frac{\partial G}{\partial p_{1}^{*}}$ is identical to $\mathcal{H}_{21}$ in the proof of Claim 2, which equals zero.

$$
\begin{aligned}
\lim _{x_{2}^{*} \rightarrow p_{2}^{*}} \frac{\partial G}{\partial p_{2}^{*}} & =-f_{1}\left(p_{1}^{*}\right)\left(1-F_{2}\left(p_{2}^{*}\right)\right)-F_{1}\left(p_{1}^{*}\right)\left(2 f_{2}\left(p_{2}^{*}\right)+p_{2}^{*} f_{2}^{\prime}\right)+\left(p_{2}^{*}-p_{1}^{*}\right) f_{1}\left(p_{1}^{*}\right) f_{2}\left(p_{2}^{*}\right) \\
& =-F_{1}\left(p_{1}^{*}\right)\left(2 f_{2}\left(p_{2}^{*}\right)+p_{2}^{*} f_{2}^{\prime}\left(p_{2}^{*}\right)\right)-p_{1}^{*} f_{1}\left(p_{1}^{*}\right) f_{2}\left(p_{2}^{*}\right) \\
& =-F_{1}\left(p_{1}^{*}\right)\left(2 f_{2}\left(p_{2}^{*}\right)+f_{2}^{\prime}\left(p_{2}^{*}\right) \frac{1-F_{2}\left(p_{2}^{*}\right)}{f_{2}\left(p_{2}^{*}\right)}\right)-p_{1}^{*} f_{1}\left(p_{1}^{*}\right) f_{2}\left(p_{2}^{*}\right)<0,
\end{aligned}
$$

where the first equality has been obtained by using $1-F_{2}\left(p_{2}^{*}\right)=p_{2}^{*} f\left(p_{2}^{*}\right)$, and the second by $p_{2}^{*}=\frac{1-F_{2}\left(p_{2}^{*}\right)}{f_{2}\left(p_{2}^{*}\right)}$. 


$$
\lim _{x_{2}^{*} \rightarrow p_{2}^{*}} \frac{\partial G}{\partial \beta_{1}}=\frac{\partial F_{1}\left(p_{1}^{*}\right)}{\partial \beta_{1}}\left(1-F_{2}\left(p_{2}^{*}\right)-p_{2}^{*} f_{2}\left(p_{2}^{*}\right)\right)=0
$$

By applying Cramer's rule, I define the signs of the derivatives of $p_{1}^{*}$ and $p_{2}^{*}$ with respect to $\beta_{1}$.

I observe that

$$
\lim _{x_{2}^{*} \rightarrow p_{2}^{*}} \frac{\partial H}{\partial p_{1}^{*}} \lim _{x_{2}^{*} \rightarrow p_{2}^{*}} \frac{\partial G}{\partial p_{2}^{*}}-\lim _{x_{2}^{*} \rightarrow p_{2}^{*}} \frac{\partial G}{\partial p_{1}^{*}} \lim _{x_{2}^{*} \rightarrow p_{2}^{*}} \frac{\partial H}{\partial p_{2}^{*}}>0
$$

Therefore,

$$
\operatorname{sgn}\left[\lim _{x_{2}^{*} \rightarrow p_{2}^{*}} \frac{\partial p_{1}^{*}}{\partial \beta_{1}}\right]=\operatorname{sgn}\left[-\lim _{x_{2} \rightarrow p_{2}^{*}} \frac{\partial H}{\partial \beta_{1}} \lim _{x_{2} \rightarrow p_{2}^{*}} \frac{\partial G}{\partial p_{2}^{*}}+\lim _{x_{2} \rightarrow p_{2}^{*}} \frac{\partial G}{\partial \beta_{1}} \lim _{x_{2} \rightarrow p_{2}^{*}} \frac{\partial H}{\partial p_{2}^{*}}\right]=1
$$

and

$$
\operatorname{sgn}\left[\lim _{x_{2}^{*} \rightarrow p_{2}^{*}} \frac{\partial p_{2}^{*}}{\partial \beta_{1}}\right]=\operatorname{sgn}\left[-\lim _{x_{2}^{*} \rightarrow p_{2}^{*}} \frac{\partial G}{\partial \beta_{1}} \lim _{x_{2}^{*} \rightarrow p_{2}^{*}} \frac{\partial H}{\partial p_{1}^{*}}+\lim _{x_{2}^{*} \rightarrow p_{2}^{*}} \frac{\partial H}{\partial \beta_{1}} \lim _{x_{2}^{*} \rightarrow p_{2}^{*}} \frac{\partial G}{\partial p_{1}^{*}}\right]=0 .
$$

To show that the profit of the monopolist is increasing in $\beta_{1}$, I apply the Envelope's theorem on the profit of the monopolist when $x_{2}^{*} \rightarrow p_{2}^{*}$. I obtain that the derivative of $\pi^{*}$ with respect to $\beta_{1}$ is positive:

$$
\lim _{x_{2}^{*} \rightarrow p_{2}^{*}} \frac{\partial \pi^{*}}{\partial \beta_{1}}=\frac{\partial F_{1}\left(p_{1}^{*}\right)}{\partial \beta_{1}}\left(p_{2}^{*}\left(1-F_{2}\left(p_{2}^{*}\right)\right)-p_{1}^{*}\right)>0
$$

If the first product is a higher-quality product, then $F_{1}(\varepsilon)<F_{2}(\varepsilon)$. Suppose that the monopolist considers obfuscating the first product. I label the prices of both goods and the value of $x_{1}$ that maximize the profit of the monopolist $p_{1}^{\prime}, p_{2}^{\prime}$ and $x_{1}^{\prime}$. Because the mean of $\varepsilon_{2}$ is lower than the mean of $\varepsilon_{1}$, despite the order effect, it may happen that $p_{2}^{\prime}<p_{1}^{\prime}$. In this case, the monopolist would set $x_{1}^{\prime}=\bar{\varepsilon}$, i.e. will not obfuscate at all. However, the firm would earn a higher profit by obfuscating its second product, because it does not find it optimal to set $x_{2}=\bar{\varepsilon}$ when $x_{1}=\bar{\varepsilon}$.

Now consider the case when the order effect is very strong and $p_{1}^{\prime}<p_{2}^{\prime}$. In this case, $x_{1}^{\prime}=p_{1}^{\prime}$ and the profit of the monopolist equals

$$
\pi^{\prime}=p_{2}^{\prime}\left(1-F_{2}\left(p_{2}^{\prime}\right)\right)+p_{1}^{\prime} F_{2}\left(p_{2}^{\prime}\right)\left(1-F_{1}\left(p_{1}^{\prime}\right)\right)
$$

The pair $\left\{p_{1}^{\prime}, p_{2}^{\prime}\right\}$ leads to a lower profit of the monopolist than the optimal one when the firm obfuscates the second product, i.e.

$$
\pi^{*}>p_{1}^{\prime}\left(1-F_{1}\left(p_{1}^{\prime}\right)\right)+p_{2}^{\prime} F_{1}\left(p_{1}^{\prime}\right)\left(1-F_{2}\left(p_{2}^{\prime}\right)\right)
$$

Next, I take the difference between the RHS of (23) and $\pi^{\prime}$. The difference is denoted by $\gamma\left(p_{1}^{\prime}, p_{2}^{\prime}, \beta_{2}\right)$. I take the derivative of $\gamma\left(p_{1}^{\prime}, p_{2}^{\prime}, \beta_{2}\right)$ with respect to $\beta_{2}$. By using the result of Claim 
5, I know that $\partial p_{1}^{\prime} / \partial \beta_{2}=0$ and $\partial p_{2}^{\prime} / \partial \beta_{2}>0$. Additionally, by taking the derivative of $\pi^{\prime}$ with respect to $\beta_{2}$ I apply the Envelope's theorem (This is not possible to do while taking the derivative of the RHS of (23) with respect to $\left.\beta_{2}\right)$. As a result the derivative of $\gamma\left(p_{1}^{\prime}, p_{2}^{\prime}, \beta_{2}\right)$ with respect to $\beta_{2}$ equals

$$
\begin{aligned}
\frac{\partial \gamma\left(p_{1}^{\prime}, p_{2}^{\prime}, \beta_{2}\right)}{\partial \beta_{2}} & =F_{1}\left(p_{1}^{\prime}\right)\left(1-F_{2}\left(p_{2}^{\prime}\right)-f_{2}\left(p_{2}^{\prime}\right) p_{2}^{\prime}\right) \frac{\partial p_{2}^{\prime}}{\partial \beta_{2}^{\prime}}-p_{2}^{\prime} F_{1}\left(p_{1}^{\prime}\right) \frac{\partial F_{2}\left(p_{2}^{\prime}\right)}{\partial \beta_{2}} \\
& -\frac{\partial F_{2}\left(p_{2}^{\prime}\right)}{\partial \beta_{2}}\left(p_{1}^{\prime}\left(1-F_{1}\left(p_{1}^{\prime}\right)\right)-p_{2}^{\prime}\right) \\
& =F_{1}\left(p_{1}^{\prime}\right)\left(1-F_{2}\left(p_{2}^{\prime}\right)-f_{2}\left(p_{2}^{\prime}\right) p_{2}^{\prime}\right) \frac{\partial p_{2}^{\prime}}{\partial \beta_{2}^{\prime}}-\frac{\partial F_{2}\left(p_{2}^{\prime}\right)}{\partial \beta_{2}}\left(1-F_{1}\left(p_{1}^{\prime}\right)\right)\left(p_{1}^{\prime}-p_{2}^{\prime}\right) .
\end{aligned}
$$

Because the second product is sampled first, then $p_{2}^{\prime}>\arg \max _{p} p\left(1-F_{2}(p)\right)$ and $1-F_{2}\left(p_{2}^{\prime}\right)-$ $f_{2}\left(p_{2}^{\prime}\right) p_{2}^{\prime}<0$. Additionally, because $p_{1}^{\prime}<p_{2}^{\prime}$, I obtain that $\partial \gamma\left(p_{1}^{\prime}, p_{2}^{\prime}, \beta_{2}\right) / \partial \beta_{2}<0$. Thus, the difference $\gamma\left(p_{1}^{\prime}, p_{2}^{\prime}, \beta_{2}\right)$ is greater than after setting $\beta_{2}=\beta_{1}$. However, if $\beta_{1}=\beta_{2}$, then the difference equals 0 . Thus, the monopolist earns more by obfuscating a lower-quality product.

Proof of proposition 4. To prove the result, I write down the pay-off function of the firm, when it $\operatorname{costs} c_{2}$ to produce product 2 and the marginal cost of product 1 equals $c_{1}$. The second expected price equals $\tilde{p}_{2}$ and product 2 is obfuscated. Then the pay-off of the monopolist equals

$$
\begin{aligned}
\tilde{\pi}\left(p_{1}, p_{2}, x_{2}\right) & =\left(p_{1}-c_{1}\right)\left[1-F\left(x_{2}-\tilde{p}_{2}+p_{1}\right)+\int_{0}^{x_{2}-\tilde{p}_{2}} F\left(\varepsilon+p_{2}\right) d F\left(\varepsilon+p_{1}\right)\right] \\
& +\left(p_{2}-c_{2}\right)\left[F\left(x_{2}-\tilde{p}_{2}+p_{1}\right)\left(1-F\left(x_{2}-\tilde{p}_{2}+p_{2}\right)\right)+\int_{0}^{x_{2}-\tilde{p}_{2}} F\left(\varepsilon+p_{1}\right) d F\left(\varepsilon+p_{2}\right)\right] .
\end{aligned}
$$

In equilibrium, the monopolist either sets $x_{2}=\tilde{p}_{2}$ or $x_{2}=\bar{\varepsilon}$. I focus here on obfuscation, and compute the first-order conditions with respect to both prices when $x_{2}=\tilde{p}_{2}, p_{2}=\tilde{p}_{2}$ and $p_{1}=\tilde{p}_{1}$. It must be that $\tilde{p}_{1}-c_{1}>\tilde{p}_{2}-c_{2}$ in this equilibrium. Both prices are given by equations (24) and $(25)$.

$$
\begin{array}{r}
1-F\left(\tilde{p}_{1}\right)-\left(\tilde{p}_{1}-c_{1}\right) f\left(\tilde{p}_{1}\right)+f\left(\tilde{p}_{1}\right)\left(\tilde{p}_{2}-c_{2}\right)\left(1-F\left(\tilde{p}_{2}\right)\right)=0 \\
1-F\left(\tilde{p}_{2}\right)-\left(\tilde{p}_{2}-c_{2}\right) f\left(\tilde{p}_{2}\right)=0
\end{array}
$$

If $\varepsilon$ is distribute uniformly in the interval $[0,1]$, then $\tilde{p}_{2}=\left(1+c_{2}\right) / 2$ and $\tilde{p}_{1}=\left(4 c_{1}+4+\left(1-c_{2}\right)^{2}\right) / 8$. The restriction $\tilde{p}_{1}-c_{1}>\tilde{p}_{2}-c_{2}$ implies that $\left(1+c_{2}\right)^{2}-4 c_{1}>0$.

Further, I compute two pay-offs. Suppose that $c_{1}=0$ and $c_{2}=c>0$. Then, the profit of the obfuscating monopolist equals $\pi_{1}=\left(c^{2}-2 c+5\right)^{2} / 64$. If $c_{1}=c$ and $c_{2}=0$, then the obfuscating monopolist earns $\pi_{2}=\left(16 c^{2}-24 c+25\right) / 64$. In the latter case it must be that $c<1 / 4$ (otherwise $p_{1}-c_{1}-p_{2}+c_{2}>0$ does not hold, and the monopolist obfuscates product 1 in equilibrium). The 
difference $\pi_{1}-\pi_{2}$ is positive for all $c<1 / 4$ :

$$
\pi_{1}-\pi_{2}=\frac{1}{64} c\left(c^{3}-4 c^{2}-2 c+4\right)>\frac{1}{64} c\left(\frac{1}{4^{3}}-\frac{4}{4^{2}}-\frac{2}{4}+4\right)=\frac{209}{64^{2}} c>0
$$

As a result, if a firm obfuscates, it obfuscates the product with a positive marginal production cost. $\square$. 